\title{
Adherence and Persistence to Adjuvant Hormonal Therapy in Early-Stage Breast Cancer Patients: A Population-Based Retrospective Cohort Study in Israel
}

\author{
Tal Sella ${ }^{a, b, d} \quad$ Gabriel Chodick ${ }^{c}$ \\ ${ }^{a}$ Department of Oncology. Sheba Medical Center, Tel Hashomer, Israel; ${ }^{b}$ The Pinchas Burstein Talpiot Medical \\ Leadership Program, Sheba Medical Center, Ramat Gan, Israel; ' ${ }^{\top}$ Medical Division, Maccabi Healthcare Services,

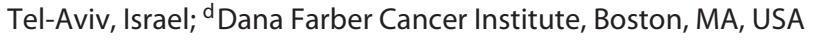

\section{Keywords}

Breast cancer - Adjuvant hormonal therapy · Adherence · Persistence - Tamoxifen survivors are comparable to those in international reports. Interventions are necessary to identify and prevent suboptimal HT adherence.

C 2019 S. Karger AG, Basel

\begin{abstract}
Background: Adjuvant hormonal therapy $(\mathrm{HT})$ has been consistently proven to improve multiple outcomes in early breast cancer yet rates of adherence and persistence are variable. Methods: We retrospectively identified women diagnosed with nonmetastatic breast cancer and initiating HT between January 2000 and December 2007 in a large Israeli health provider. Prescription records including the drug name, date of purchase, and the quantity of pills dispensed were collected. We used Cox proportional hazards and binary logistic models to analyze factors associated with early discontinuation ( $<5$ years) and nonadherence (proportion of days covered, PDC $<80 \%$ ) of HT, respectively. Results: A total of 4,178 women with breast cancer were identified with nearly $95 \%$ of patients treated with tamoxifen as the initial HT. Over the 5-year follow-up period, early discontinuation was identified in 955 (23\%) patients. The mean PDC was $82.9 \%$ (SD 0.004). Younger age and low BMI were both associated with an increased risk of early discontinuation and nonadherence. A history of hypertension was associated with a higher likelihood of both outcomes. Conclusion: Adherence and persistence with HT among Israeli breast cancer
\end{abstract}

\section{Introduction}

The benefits of adjuvant hormonal therapy (HT) in women diagnosed with early-stage hormone receptorpositive breast cancer (BC) have been well documented in numerous clinical trials. Tamoxifen, the traditional standard, was shown to reduce risks of systemic recurrence and contralateral $\mathrm{BC}$ while reducing the annual $\mathrm{BC}$ death rate by $31 \%$ [1]. Since then, additional strategies, such as aromatase inhibitors (AI), ovarian suppression, and extended HT beyond 5 years have been shown to further improve long-term outcomes [2-4].

To be effective in achieving the desired effects, the prescribed regimens must be complied with, a simple prerequisite that for oral medications can become a major obstacle. Compliance in this sense is composed of adherence, a measure of how well the patient takes the medication compared with physician instructions (daily for adjuvant HT), and persistence, the overall time the patient takes the medicine from commencement to discontinuation [5]. Despite the proven survival benefit of adju- 
vant HT, a substantial proportion of patients discontinue treatment. While HT adherence is relatively high in adjuvant trials, adherence to $\mathrm{HT}$ in clinical practice is relatively poor, with about $50 \%$ of women successfully completing 5 years of HT [6]. In one review of 24 articles published between 2000 and 2012, rates of adherence were variable, ranging from 45 to $93.4 \%$ with tamoxifen and 62 to $94.7 \%$ for AI. Rates of discontinuation ranged from 15 to $60 \%$ and 18.9 to $24.7 \%$ respectively [7]. Both early discontinuation and nonadherence to HT are associated with increased $\mathrm{BC}$ recurrence and mortality [8-10].

To date, rates of adherence and discontinuation of adjuvant $\mathrm{HT}$ among Israeli $\mathrm{BC}$ subjects have not been reported. Among the community of oncology experts, these rates are thought to be high, yet this premonition is unsubstantiated. An analogous scenario can be found in the prescription of statins for the secondary prevention of coronary heart disease for which rates of persistence at 2 years have been reported to be under $75 \%$ in Israel [11], indicating that high adherence may not be the Israeli standard. Since oral therapeutic agents are increasingly being developed and used in long-term management of malignancies, the local patterns of compliance need to be clarified [12]. Due to its cardinal role in the treatment of early $\mathrm{BC}$, we aimed to assess the adherence and persistence of Israeli BC patients with adjuvant $\mathrm{HT}$ by conducting a retrospective cohort study among members of Maccabi Healthcare Services (MHS).

\section{Materials and Methods}

\section{Data Source}

MHS is the second largest health maintenance organization (HMO) in Israel, currently insuring approximately 2 million members countrywide - approximately $25 \%$ of the Israeli population [13]. According to the Israeli National Health Insurance Act, every citizen is provided public health insurance by one of four state-funded HMOs, which are not permitted to bar any applicant. Thus, a range of ethnic, socioeconomic, and geographic population groups are represented in MHS. The study was reviewed and approved by the MHS institutional review board,

An electronic medical record, indexed by each member's unique national identification number, has been implemented in MHS since 1995 logging all members' demographic data, physician visits, hospitalizations, procedures, laboratory results, and filled prescriptions. Members may fill prescriptions at any MHS or contracted pharmacy throughout the country with a minimum copayment of USD 3 per prescription fill. In addition, MHS has developed and validated computerized registries of patients suffering from major chronic diseases, including cardiovascular disease (CVD), chronic kidney disease (CKD), hypertension, diabetes mellitus (DM), and cancer [14]. The later registry is continuously updated with data derived from the Israel National Cancer Register (INCR). Established in 1960, the INCR collects information on invasive and in situ cancer cases diagnosed in medical institutions throughout the country with a reported completeness of $94.2 \%$ for BC [15].

\section{Study Population}

We identified all women in the MHS database diagnosed with BC between 2000 and 2007, as reported by the INCR. In order to only include patients with local/locally advanced hormone receptor-positive BC, our sample was restricted to women who underwent curative breast surgery (lumpectomy/mastectomy) and filed at least one prescription for HT (tamoxifen, anastrozole, letrozole, exemestane) within 12 months after diagnosis. Patients were followed from the date their first prescription was dispensed until diagnosis of recurrent disease, leaving MHS, death, or completion of 5 years of treatment. Recurrent disease was defined as any of the following events - breast surgery (lumpectomy/mastectomy) or administration of any chemotherapy or radiotherapy more than a year from the initialization of HT, HT indicated for metastatic disease (i.e., fulvestrant, everolimus), or IV anti-bone resorption agents (i.e., zoledronate, denosumab).

\section{Prescription Data}

We collected data on all prescriptions filed for approved oral HT (tamoxifen, anastrozole, letrozole, exemestane). Prescription records included the drug name, date of purchase, and the quantity of pills dispensed.

\section{Study Definitions}

The date adjuvant HT was first dispensed was considered the index date. To allow a direct comparison with previous studies, we categorized patients as having discontinued therapy if 180 or more days had elapsed from their prior prescription to refill or to last day of follow-up $[16,17]$. Adherence with medication refers to the extent of drug use during the period of persistence and is often estimated by mean proportion of days covered (PDC). We calculated PDC by dividing the quantity of pills dispensed by the total time interval from the index date to the end of follow-up. Rates greater than $100 \%$ were capped at $100 \%$. Subjects with a PDC $\geq 80 \%$ were categorized as adherent as defined in previously published literature [16].

\section{Study Covariates}

The following variables were examined for a possible association with adherence and persistence to adjuvant HT:

Sociodemographic Variables. Age at HT initiation was categorized as $<45,45-55,55-65,65-75$, and $>85$ years. Patients were classified by district of residence (North, South, Center, Sharon, Jerusalem area, Others) and country of birth (Israel, Europe, Asia/ Africa, Others). Socioeconomic status was categorized into quartiles according to the poverty index of the member's enumeration area (a small unit of area used for collecting, recording, and reporting census data), as defined in the 1995 national census based on household income, educational qualifications, crowding, material conditions, and vehicle ownership.

Clinical Variables. Comorbid diseases were identified through MHS registries and included DM, CVD, CKD, hypertension, osteoporosis, thrombosis, or uterine cancer. Body mass index (BMI) was ascertained and categorized as underweight $(<18.5)$, normal (18.5-24.99), overweight (25-29.99) and obese ( $\geq 30)$. Cigarette smokers were categorized as current, past, or never smokers. In addition, patients were categorized by type of HT (tamoxifen/AI) and year of therapy initiation (2000-2008).

\section{Statistical Analyses}

Population characteristics were described by means and proportions. Univariate and multivariate Cox proportional hazards regression models were applied to analyze the association between rates of persistence to HT with subject sociodemographic and clinical factors. We used univariate and multivariate logistic regression to analyze the associations with adherence, classified as a di- 
chotomous variable (PDC $\geq 80 \%$ vs. $\mathrm{PDC}<80 \%$ ). Hazard ratios (HR) or odds ratios (OR), 95\% confidence intervals (95\% CI), and $p$ values were calculated for all variables. Kaplan-Meier curves were generated to estimates rates of discontinuation over time. All statistical analyses were performed using SPSS v.23.0 (IBM Corp., Armonk, NY, USA).

\section{Results}

We identified 4,178 women who were diagnosed with BC in MHS between January 1, 2000, and December 30, 2007 and underwent breast surgery and initiated HT with 12 months of diagnosis. During the 5-year follow-up period from treatment initialization, 635 (15\%) women had a disease recurrence, 208 (5\%) women died, and 17 (4\%) left MHS. Recurrence was indicated by surgery in 212 (33\%) women, radiation in $180(28 \%)$ women, and chemotherapy or other medications indicated for metastatic disease in 243 (38\%) women.

Of the 4,178 patients included in the cohort, 3,938 (94\%) were initially treated with tamoxifen, while 240 (6\%) received an AI. The proportion of patients initializing adjuvant therapy with an AI significantly increased from $1.3 \%$ in 2000 to $9.5 \%$ by 2008 ( $p=0.001)$.

The study population was diverse, with $47 \%$ born in Israel and $40 \%$ of immigrants coming from Europe. The mean age was 57.39 (SD 12.63) with $16 \%$ of subjects $\leq 45$ years of age and $9.6 \%>75$ years. Most of the population was geographically based in central Israel $-64.6 \%$ in the Center, Jerusalem area, and Sharon districts and only $18 \%$ and $13 \%$, respectively, in the peripheral Northern and Southern districts. The study population was generally healthy with hypertension being the most common comorbidity (35\%) and only $9.5 \%$ of patients reporting a history of smoking. Baseline population characteristics are fully detailed in Table 1 .

\section{Discontinuation}

Over the 5-year follow-up period, early discontinuation was identified in 955 (23\%) patients. Rates of discontinuation were stable throughout the study period and ranged from $21 \%$ in 2000 to $26 \%$ in 2008 . The proportion of patients who continued therapy decreased from $92 \%$ in year 1 to $75 \%$ in year 4 (Fig. 1).

In unadjusted univariate analysis discontinuation was positively correlated with age, with all age groups significantly less likely to discontinue compared to the youngest age group - women $\leq 45$ years of age (Table 2). Underweight BMI had a borderline significant association with early discontinuation (HR 2.07, 95\% CI: 1.70-2.25, $p=$ 0.07 ) of treatment while overweight BMI (HR $0.84,95 \%$ CI: $0.71-0.99, p=0.03$ ) and obesity (HR $0.82,95 \%$ CI: $0.69-0.98, p=0.03$ ) were both negatively correlated with discontinuation compared to normal BMI. Patients with
Table 1. Baseline characteristics of patients diagnosed with breast cancer and treated with adjuvant endocrine therapy, MHS, 20002007

\begin{tabular}{|c|c|c|}
\hline \multirow{2}{*}{$\begin{array}{l}\text { Age }(\text { mean } \pm S D) \text {, years } \\
\text { Age }\end{array}$} & \multicolumn{2}{|c|}{$57.39 \pm 12.63$} \\
\hline & & \\
\hline$\leq 45.00$ years & 667 & 16.00 \\
\hline $45.01-55$ years & 1,266 & 30.30 \\
\hline $55.01-65$ years & 1,072 & 25.70 \\
\hline $65.01-75$ years & 770 & 18.40 \\
\hline $75.01-85$ years & 352 & 8.40 \\
\hline $85.01+$ years & 51 & 1.20 \\
\hline \multicolumn{3}{|l|}{ SES } \\
\hline Lowest quartile & 1,300 & 33.80 \\
\hline Second quartile & 855 & 22.30 \\
\hline Third quartile & 942 & 24.50 \\
\hline Highest quartile & 745 & 19.40 \\
\hline \multicolumn{3}{|l|}{ Birth country } \\
\hline Israel & 1,982 & 47.40 \\
\hline Europe & 1,672 & 40.00 \\
\hline Asia/Africa & 339 & 8.10 \\
\hline Other/unknown & 185 & 4.40 \\
\hline \multicolumn{3}{|l|}{ District } \\
\hline Southern & 543 & 13.00 \\
\hline Northern & 756 & 18.10 \\
\hline Sharon & 840 & 20.10 \\
\hline Jerusalem area & 951 & 22.80 \\
\hline Other & 182 & 4.40 \\
\hline Central & 906 & 21.70 \\
\hline \multicolumn{3}{|l|}{ BMI } \\
\hline Underweight & 460 & 11.00 \\
\hline Normal & 1,244 & 29.80 \\
\hline Overweight & 1,344 & 32.20 \\
\hline Obese & 1,130 & 27.00 \\
\hline \multicolumn{3}{|l|}{ Smoking history } \\
\hline Current & 298 & 7.10 \\
\hline Past & 101 & 2.40 \\
\hline Never & 3,570 & 85.40 \\
\hline Other/unknown & 209 & 5.00 \\
\hline \multicolumn{3}{|l|}{ Initial treatment } \\
\hline Tamoxifen & 3,938 & 94.30 \\
\hline AI & 240 & 5.70 \\
\hline \multicolumn{3}{|l|}{ Year of initial treatment } \\
\hline 2000 & 233 & 5.60 \\
\hline 2001 & 458 & 11.00 \\
\hline 2002 & 461 & 11.00 \\
\hline 2003 & 467 & 11.20 \\
\hline 2004 & 457 & 10.90 \\
\hline 2005 & 592 & 14.20 \\
\hline 2006 & 603 & 14.40 \\
\hline 2007 & 623 & 14.90 \\
\hline 2008 & 284 & 6.80 \\
\hline Hypertension & 1,444 & 34.60 \\
\hline Osteoporosis & 590 & 14.10 \\
\hline Chronic kidney disease & 332 & 7.90 \\
\hline Cardiovascular disease & 448 & 10.70 \\
\hline Diabetes mellitus & 501 & 12.00 \\
\hline
\end{tabular}

Data are presented as $n(\%)$ unless otherwise indicated. SES, socioeconomic status. 
Fig. 1. Kaplan-Meier curve for continuation of hormonal therapy.

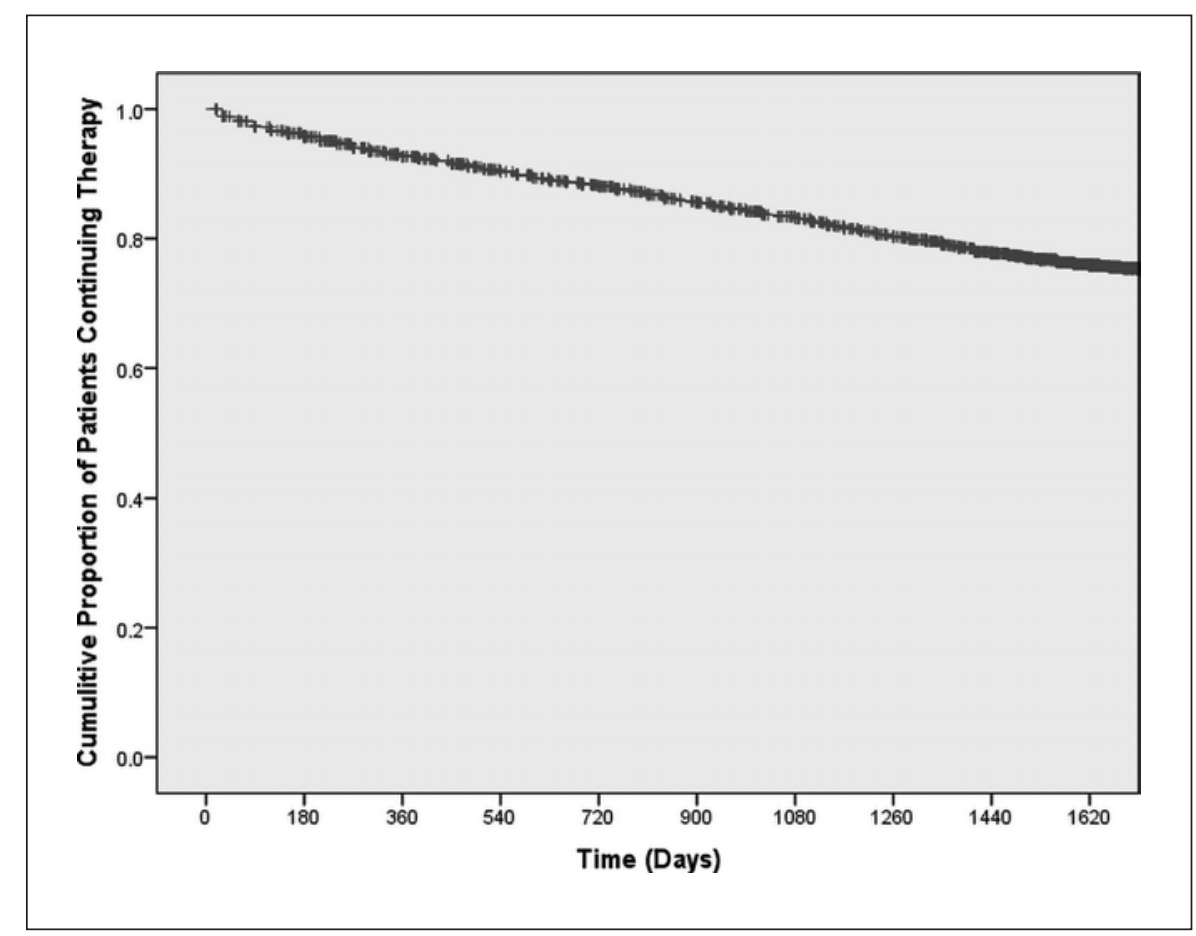

comorbidities (osteoporosis, hypertension, diabetes) were less likely to discontinue treatment. Specifically, a diagnosis of hypertension was associated with a $0.68 \mathrm{HR}$ (95\% CI: $0.59-0.79, p<0.001)$ for discontinuation. Significant univariate correlations were also identified for country of birth, district, and smoking status.

A multivariate Cox proportional hazards analysis was also performed to determine predictors of early discontinuation (Table 2). Underweight BMI was associated with an increased risk for early discontinuation of HT (HR 2.34, 95\% CI: 1.85-2.97, compared to normal BMI), while older age, comorbid hypertension (HR 0.74, 95\% CI: $0.62-0.89$, compared to no hypertension), and unknown smoking status (HR 1.45, 95 CI: 1.07-1.97, compared to never smoking) were all associated with persistence with 5 years of HT.

\section{Adherence}

The mean PDC over the 5-year follow-up period was 82.9\% (SD 0.004). PDC remained stable throughout the study period, ranging from $81.4 \%$ in 2000 to $84.1 \%$ in $2008(p=0.349)$.

In unadjusted univariate analysis, older age, birth outside of Israel, higher BMI, initial treatment with AI, hypertension, osteoporosis, and DM were all associated with increased odds of adherence (Table 3). Active smoking was negatively correlated with adherence. The strongest predictor for adherence was age between 65.01 and 75 years (OR 3.24, 95\% CI: 2.55-4.10, $p<0.001$, compared to women $\leq 45$ years of age).
When adjusting for all variables, older age significantly increased the chance of adherence (Table 3 ). Compared to the youngest age group ( $\leq 45$ years), the OR for adherence progressively increased with age and was highest among the age group $65.01-75$ years (OR 2.49, 95\% CI: $1.84-3.37, p<0.001$ ) before declining thereafter (OR 2.14, 95\% CI: $1.46-3.14, p<0.001$, for women aged 75.01-85 years). A history of hypertension (HR 1.46, 95\% CI: 1.19$1.79, p<0.001)$ was also positively associated with adherence. Underweight BMI (OR 0.48, 95\% CI: 0.36-0.63, $p<$ 0.001 , compared to normal BMI) and active smoking (OR $0.70,95 \%$ CI: $0.53-0.91, p<0.001$, compared to never smoking) were negatively correlated with adherence.

\section{Discussion}

In this large population-based study of women with early-stage $\mathrm{BC}$ enrolled in a nationwide health organization, we found that approximately $20 \%$ of new users of adjuvant HT, mostly with tamoxifen, discontinued therapy early. Nearly three-fourths of the population were full adherent to five years of therapy. Rates of discontinuation and nonadherence were highest among young $(\leq 45$ years) and underweight women.

Numerous studies have shown high discontinuation and nonadherence rates among women on adjuvant HT. In a review of 24 articles published between 2000 and 2012, rates of adherence and discontinuation with tamoxifen ranged from 45 to $93.4 \%$ and from 15 to $60 \%$, respec- 
Table 2. Univariate and multivariate analysis of predictors of hormonal therapy discontinuation among women diagnosed with breast cancer and treated with adjuvant hormonal therapy, MHS, 2000-2007

\begin{tabular}{|c|c|c|c|c|c|c|}
\hline \multirow[b]{2}{*}{ Covariate } & \multicolumn{3}{|c|}{ Univariate } & \multicolumn{3}{|c|}{ Multivariate } \\
\hline & HR & $95 \% \mathrm{CI}$ & $p$ & HR & $95 \%$ CI & $p$ \\
\hline \multicolumn{7}{|l|}{ Age } \\
\hline$\leq 45$ years & 1.00 & & & 1.00 & & \\
\hline $45.01-55$ years & 0.57 & $0.48-0.68$ & 0.00 & 0.65 & $0.54-0.79$ & 0.00 \\
\hline $55.01-65$ years & 0.47 & $0.39-0.57$ & 0.00 & 0.59 & $0.47-0.74$ & 0.00 \\
\hline $65.01-75$ years & 0.49 & $0.40-0.60$ & 0.00 & 0.66 & $0.51-0.86$ & 0.00 \\
\hline $75.01-85$ years & 0.62 & $0.48-0.80$ & 0.00 & 0.69 & $0.49-0.97$ & 0.03 \\
\hline $85.01+$ years & 0.82 & $0.47-1.44$ & 0.50 & 0.74 & $0.40-1.37$ & 0.34 \\
\hline \multicolumn{7}{|l|}{ SES } \\
\hline Lowest quartile & 1.00 & & & & 1.00 & \\
\hline Second quartile & 0.98 & $0.81-1.18$ & 0.82 & 0.96 & $0.79-1.16$ & 0.67 \\
\hline Third quartile & 1.15 & $0.96-1.36$ & 0.13 & 1.06 & $0.88-1.27$ & 0.57 \\
\hline Highest quartile & 1.01 & $0.83-1.22$ & 0.94 & 0.89 & $0.72-1.11$ & 0.30 \\
\hline \multicolumn{7}{|l|}{ Birth country } \\
\hline Israel & 1.00 & & & & 1.00 & \\
\hline Europe & 0.82 & $0.72-0.94$ & 0.01 & 0.92 & $0.78-1.08$ & 0.31 \\
\hline Asia/Africa & 0.70 & $0.54-0.90$ & 0.01 & 0.86 & $0.65-1.14$ & 0.29 \\
\hline Other/unknown & 0.75 & $0.53-1.05$ & 0.09 & 0.84 & $0.58-1.21$ & 0.35 \\
\hline \multicolumn{7}{|l|}{ District } \\
\hline Central & 1.00 & & & & 1.00 & \\
\hline Southern & 0.81 & $0.65-1.02$ & 0.07 & 0.82 & $0.64-1.05$ & 0.12 \\
\hline Northern & 0.94 & $0.77-1.15$ & 0.55 & 0.96 & $0.77-1.19$ & 0.69 \\
\hline Sharon & 0.87 & $0.72-1.06$ & 0.17 & 0.85 & $0.69-1.04$ & 0.11 \\
\hline Jerusalem area & 0.84 & $0.69-1.01$ & 0.06 & 0.84 & $0.68-1.03$ & 0.09 \\
\hline Other & 2.13 & $1.59-2.85$ & 0.00 & & & \\
\hline \multicolumn{7}{|l|}{ BMI } \\
\hline Underweight & 2.07 & $1.70-2.52$ & 0.00 & 2.34 & $1.85-2.97$ & 0.00 \\
\hline Normal & 1.00 & & & & 1.00 & \\
\hline Overweight & 0.84 & $0.71-0.99$ & 0.03 & 0.96 & $0.81-1.15$ & 0.68 \\
\hline Obese & 0.82 & $0.69-0.98$ & 0.03 & 1.02 & $0.84-1.24$ & 0.86 \\
\hline \multicolumn{7}{|l|}{ Smoking history } \\
\hline Current & 1.26 & $1.00-1.58$ & 0.05 & 1.19 & $0.93-1.52$ & 0.16 \\
\hline Past & 1.10 & $0.73-1.65$ & 0.65 & 1.13 & $0.74-1.73$ & 0.57 \\
\hline Never & 1.00 & & & & 1.00 & \\
\hline Other/unknown & 1.80 & $1.38-2.33$ & 0.00 & 1.45 & $1.07-1.97$ & 0.02 \\
\hline \multicolumn{7}{|l|}{ Initial treatment } \\
\hline Tamoxifen & 1.00 & & & & 1.00 & \\
\hline $\mathrm{AI}$ & 1.10 & $0.83-1.45$ & 0.52 & 1.15 & $0.85-1.55$ & 0.38 \\
\hline \multicolumn{7}{|c|}{ Year of initial treatment } \\
\hline 2000 & 1.00 & & & & 1.00 & \\
\hline 2001 & 1.25 & $0.90-1.73$ & 0.19 & 1.15 & $0.81-1.64$ & 0.44 \\
\hline 2002 & 1.12 & $0.81-1.57$ & 0.49 & 1.09 & $0.76-1.56$ & 0.63 \\
\hline 2003 & 0.99 & $0.71-1.40$ & 0.97 & 1.07 & $0.74-1.55$ & 0.71 \\
\hline 2004 & 1.07 & $0.77-1.50$ & 0.68 & 1.05 & $0.73-1.52$ & 0.79 \\
\hline 2005 & 0.93 & $0.67-1.29$ & 0.67 & 1.02 & $0.71-1.45$ & 0.93 \\
\hline 2006 & 1.01 & $0.73-1.39$ & 0.96 & 1.15 & $0.81-1.63$ & 0.44 \\
\hline 2007 & 1.07 & $0.77-1.47$ & 0.69 & 1.17 & $0.82-1.66$ & 0.39 \\
\hline 2008 & 1.19 & $0.83-1.71$ & 0.34 & 1.33 & $0.90-1.96$ & 0.15 \\
\hline \multicolumn{7}{|l|}{ Hypertension } \\
\hline No & 1.00 & & & & 1.00 & \\
\hline Yes & 0.68 & $0.59-0.79$ & 0.00 & 0.74 & $0.62-0.89$ & 0.00 \\
\hline \multicolumn{7}{|l|}{ Osteoporosis } \\
\hline No & 1.00 & & & & 1.00 & \\
\hline Yes & 0.76 & $0.62-0.93$ & 0.01 & 0.84 & $0.67-1.05$ & 0.12 \\
\hline \multicolumn{7}{|c|}{ Chronic kidney disease } \\
\hline No & 1.00 & & & & 1.00 & \\
\hline Yes & 0.93 & $0.73-1.19$ & 0.55 & 1.09 & $0.83-1.44$ & 0.54 \\
\hline Cardiovascular disea & & & & & & \\
\hline No & 1.00 & & & & 1.00 & \\
\hline Yes & 0.90 & $0.73-1.12$ & 0.36 & 1.11 & $0.87-1.42$ & 0.41 \\
\hline Diabetes mellitus & & & & & & \\
\hline No & 1.00 & & & & 1.00 & \\
\hline Yes & 0.79 & $0.64-0.98$ & 0.03 & 1.02 & $0.80-1.29$ & 0.90 \\
\hline
\end{tabular}


Table 3. Univariate and multivariate analysis of predictors of hormonal therapy adherence among women diagnosed with breast cancer and treated with adjuvant hormonal therapy, MHS, 2000-2007

\begin{tabular}{|c|c|c|c|c|c|c|}
\hline & \multicolumn{3}{|c|}{ Univariate } & \multicolumn{3}{|c|}{ Multivariate } \\
\hline & OR & $95 \%$ CI & $p$ & OR & $95 \%$ CI & $p$ \\
\hline \multicolumn{7}{|l|}{ Age } \\
\hline$\leq 45.00$ years & 1.00 & & & 1.00 & & \\
\hline $45.01-55$ years & 1.89 & $1.55-2.30$ & 0.000 & 1.71 & $1.38-2.13$ & 0.000 \\
\hline $55.01-65$ years & 3.03 & $2.44-3.75$ & 0.000 & 2.41 & $1.87-3.10$ & 0.000 \\
\hline $65.01-75$ years & 3.24 & $2.55-4.10$ & 0.000 & 2.49 & $1.84-3.37$ & 0.000 \\
\hline $75.01-85$ years & 2.29 & $1.72-3.05$ & 0.000 & 2.14 & $1.46-3.14$ & 0.000 \\
\hline $85.01+$ years & 1.16 & $0.65-2.08$ & 0.610 & 1.27 & $0.65-2.50$ & 0.481 \\
\hline \multicolumn{7}{|l|}{ SES } \\
\hline Lowest quartile & 1.00 & & & 1.00 & & \\
\hline Second quartile & 0.95 & $0.78-1.16$ & 0.643 & 0.99 & $0.81-1.22$ & 0.956 \\
\hline Third quartile & 1.03 & $0.85-1.24$ & 0.787 & 1.14 & $0.92-1.41$ & 0.226 \\
\hline Highest quartile & 1.07 & $0.87-1.31$ & 0.546 & 1.23 & $0.96-1.56$ & 0.097 \\
\hline \multicolumn{7}{|l|}{ Birth country } \\
\hline Israel & 1.00 & & & & 1.00 & \\
\hline Europe & 1.26 & $1.09-1.46$ & 0.002 & 1.01 & $0.84-1.20$ & 0.929 \\
\hline Asia/Africa & 1.36 & $1.04-1.78$ & 0.026 & 0.99 & $0.74-1.33$ & 0.955 \\
\hline Other/unknown & 1.50 & $1.04-2.15$ & 0.030 & 1.22 & $0.82-1.82$ & 0.326 \\
\hline \multicolumn{7}{|l|}{ District } \\
\hline Central & 1.00 & & & 1.00 & & \\
\hline Southern & 1.17 & $0.92-1.50$ & 0.208 & 1.25 & $0.95-1.66$ & 0.114 \\
\hline Northern & 0.96 & $0.77-1.19$ & 0.700 & 0.97 & $0.76-1.24$ & 0.817 \\
\hline Sharon & 1.08 & $0.88-1.34$ & 0.455 & 1.10 & $0.88-1.38$ & 0.398 \\
\hline Jerusalem area & 1.06 & $0.86-1.31$ & 0.567 & 1.10 & $0.87-1.39$ & 0.410 \\
\hline Other & 0.60 & $0.43-0.84$ & 0.003 & - & & \\
\hline \multicolumn{7}{|l|}{ BMI } \\
\hline Underweight & 0.54 & $0.43-0.67$ & 0.000 & 0.48 & $0.36-0.63$ & 0.000 \\
\hline Normal & 1.00 & & & 1.00 & & \\
\hline Overweight & 1.23 & $1.03-1.47$ & 0.020 & 1.08 & $0.89-1.32$ & 0.414 \\
\hline Obese & 1.27 & $1.06-1.53$ & 0.011 & 1.00 & $0.81-1.24$ & 0.982 \\
\hline \multicolumn{7}{|l|}{ Smoking history } \\
\hline Current & 0.63 & $0.49-0.80$ & 0.000 & 0.70 & $0.53-0.91$ & 0.009 \\
\hline Past & 1.02 & $0.65-1.61$ & 0.932 & 0.90 & $0.55-1.47$ & 0.681 \\
\hline Never & 1.00 & & & & 1.00 & \\
\hline Other/unknown & 0.49 & $0.37-0.65$ & 0.000 & 0.58 & $0.40-0.82$ & 0.002 \\
\hline \multicolumn{7}{|l|}{ Initial treatment } \\
\hline Tamoxifen & 1.00 & & & 1.00 & & \\
\hline AI & 1.44 & $1.04-1.99$ & 0.026 & 1.26 & $0.88-1.81$ & 0.210 \\
\hline \multicolumn{7}{|c|}{ Year of initial treatment } \\
\hline 2000 & 1.00 & & & 1.00 & & \\
\hline 2001 & 1.01 & $0.71-1.42$ & 0.970 & 0.99 & $0.68-1.46$ & 0.979 \\
\hline 2002 & 1.11 & $0.78-1.57$ & 0.568 & 1.02 & $0.69-1.50$ & 0.929 \\
\hline 2003 & 1.30 & $0.92-1.85$ & 0.140 & 1.19 & $0.80-1.77$ & 0.379 \\
\hline 2004 & 1.12 & $0.79-1.58$ & 0.532 & 1.04 & $0.70-1.54$ & 0.838 \\
\hline 2005 & 1.20 & $0.86-1.67$ & 0.295 & 1.05 & $0.72-1.53$ & 0.808 \\
\hline 2006 & 1.25 & $0.89-1.75$ & 0.196 & 1.01 & $0.70-1.48$ & 0.943 \\
\hline 2007 & 1.25 & $0.89-1.74$ & 0.193 & 1.09 & $0.75-1.60$ & 0.647 \\
\hline 2008 & 1.11 & $0.76-1.63$ & 0.590 & 1.04 & $0.67-1.59$ & 0.871 \\
\hline \multicolumn{7}{|l|}{ Hypertension } \\
\hline No & 1.00 & & & 1.00 & & \\
\hline Yes & 1.78 & $1.53-2.08$ & 0.000 & 1.46 & $1.19-1.79$ & 0.000 \\
\hline \multicolumn{7}{|l|}{ Osteoporosis } \\
\hline No & 1.00 & & & 1.00 & & \\
\hline Yes & 1.41 & $1.14-1.74$ & 0.001 & 1.07 & $0.84-1.36$ & 0.590 \\
\hline \multicolumn{7}{|c|}{ Chronic kidney disease } \\
\hline No & 1.00 & & & 1.00 & & \\
\hline Yes & 1.20 & $0.92-1.56$ & 0.184 & 0.91 & $0.67-1.24$ & 0.547 \\
\hline \multicolumn{7}{|l|}{ Cardiovascular disease } \\
\hline No & 1.00 & & & 1.00 & & \\
\hline Yes & 1.16 & $0.92-1.45$ & 0.208 & 0.89 & $0.68-1.17$ & 0.419 \\
\hline Diabetes mellitus & & & & & & \\
\hline No & 1.00 & & & 1.00 & & \\
\hline Yes & 1.38 & $1.10-1.73$ & 0.005 & 0.92 & $0.71-1.19$ & 0.520 \\
\hline
\end{tabular}


tively [7]. While patient populations and study definitions vary, our findings fall within the upper limits of these ranges and indicate an overall satisfactory compliance within the Israeli population. Rates of adherence and discontinuation were not associated with socioeconomic status, geographic district, or place of birth. The lack of such an association can be taken to reflect the equality in access, distribution, and quality of health services in Israel. Specifically, our results are consistent with those reported by KPNC, a similar health organization where all patients are covered by a prescription health plan and have access to health care, and which is thus a good comparator [16].

Similar to previous studies, we found that patients at extremes of age were most likely to discontinue HT or be nonadherent. Women $\leq 45$ years of age were particularly at risk for nonadherence and early discontinuation. While this finding is less prominent in clinical trial populations $[10,18]$, it has also been described in large populationbased studies [16, 17, 19, 20]. In Kaiser Permanente, women younger than 40 years had the highest risk of discontinuation (HR 1.51; 95\% CI: $1.23-1.85$ ) and at 4.5 years of follow-up, $32 \%$ had discontinued therapy $[8,16]$. In a prospective cohort of women less than 40 years of age initiating adjuvant tamoxifen, more than 1 in 5 either did not initiate treatment or definitively stopped taking it in the months following their first prescription [19]. The fact that younger patients are more likely to stop taking adjuvant $\mathrm{HT}$ is of particular concern as these women are at greater risk of recurrence owing to more aggressive, higher-grade tumors as well as increased mortality [21, 22]. Treatment interruptions and nonadherence may also have a greater impact on mortality among younger BC patients [23]. Young women with $\mathrm{BC}$ have been recognized as a vulnerable subgroup, facing complex and unique oncological, surgical, fertility, genetic, psychosocial, and lifestyle factors which should be addressed to ensure optimal outcomes [24]. Concerns relating to fertility and side effects are common reasons for noninitiation or discontinuation of HT among premenopausal BC survivors [25]. We could not comment on pregnancies or toxicity burden in the current cohort. Thromboembolism and uterine cancers, two significant risks associated with tamoxifen, however, were diagnosed in $2.3 \%(n=95)$ and $0.5 \%(n=20)$ of subjects during follow-up.

The association between comorbidity and adherence is complex. Increasing comorbidity has been shown to increase adherence to certain medication classes while decreasing adherence to others [26]. In a review of 29 studies the effect of comorbidity on adherence to adjuvant $\mathrm{HT}$ in clinical practice was mixed, with most studies reporting no association [27]. For example, Partridge at al. [20] found a higher Charlson comorbidity index to be associated with better adherence in a Medicaid popula- tion while a negative association with adherence was observed in KPNC $[16,20]$. In our cohort, a diagnosis of hypertension was significantly associated with higher adherence to HT and a lower risk of discontinuation. No effect was observed for diabetes, CVD, CKD, or osteoporosis. Patients with cancer with significant comorbidities have higher prevalence of polypharmacy, placing them at risk for drug-drug interactions, adverse drug events, hospitalizations, and increased mortality [28]. In a retrospective cohort study of 40,009 women initiating adjuvant endocrine therapy between 2009 and 2013 in the Truven Health MarketScan Database, increasing polypharmacy and pill burden were associated with greater adherence [29]. Effects, however, differed by medication class. In coherence with our observation, the frequent use of antihypertensives was associated with higher odds of adherence. A similar association was also found for the use of lipidlowering drugs, while the use of opioid-containing analgesics, anxiolytics/antipsychotics, antidepressants, and insulin therapy was associated with lower odds of adherence. Thus, the use of other therapies, such as lipid-lowering and antihypertensive drugs, may indicate healthy users who are more concerned for their health and predisposed to follow medical advice including adherence to HT.

Previous clinical studies have rarely explored the effect of BMI on the adherence to HT [27]. Most studies have focused on overweight women, underrepresenting underweight women or classifying them as normal BMI [30]. We found similar rates of adherence and nondiscontinuation among women with normal or overweight BMI. Underweight women, however, had a significantly increased risk for both behaviors. In one of the few studies specifically designed to evaluate this issue, Kann et al. [31] identified increasing BMI as a significant predictor for persistence of HT (OR 1.35, 95\% CI: 1.08-1.80, $p=$ 0.042). Similar findings were found in Switzerland, where increasing BMI was positively associated with compliance and persistence to endocrine therapy. Authors have postulated that overweight/obese patients who may be already taking chronic medications for comorbidities may be more compliant with additional drugs. Women with low BMI may also be more apprehensive of weight gain which may be associated with HT [32].

The major strengths of our study include a populationbased design and large sample size. We used detailed prescription claims databases with exact pill counts thus avoiding calculation assumptions made in previous studies [16]. The use of prescription claims databases to estimate medication adherence has been validated in other studies [33]. However, the existence of a claim does not ensure the drug was consumed, possibly creating a nondifferential information bias. Furthermore, we could not comment on patients who did not file at least one pre- 
scription for HT. Thus, our results do not include patients with hormone receptor-positive $\mathrm{BC}$ who received a recommendation yet opted not to initiate HT. We used administrative databases to collect extensive sociodemographic and medical data; however, apart from the diagnosis of BC they could not produce reliable data on cancer stage or treatment. To identify early-stage BCs, we limited our population to women who underwent breast surgery immediately following their cancer diagnosis. A similar approach has been reliably applied in other studies $[16,34]$. We used a prospective study design and followed patients through 5 years of therapy. While we were unable to determine the reasons for nonadherence and discontinuation, by using MHS's comprehensive administrative databases we were able to ascertain events of death, leaving the health plan, and disease recurrence. $\mathrm{BC}$ recurrences are not routinely registered in the INCR and their ascertainment with electronic medical data is challenging. We used a wide definition for $\mathrm{BC}$ recurrence based on breast surgeries, radiotherapy, and chemotherapy. Similar definitions have been shown to provide high sensitivity at the price of a high rate of misclassification [35].

Overall, we observed relatively high rates of adherence and persistence with adjuvant $\mathrm{HT}$ among Israeli $\mathrm{BC}$ patients. However, we were able to identify several at-risk populations. Characteristics that suggest a "healthier" patient (being younger, thinner, and without comorbidity) were all associated with lower odds of adherence and higher risk of discontinuation of HT. This may imply that acceptance of a "chronic illness" diagnosis and the potential consequences may be an important determinant of medication-taking behavior. Interventional strategies to promote adherence, as well as to effectively communicate the harms and benefits of HT to patients, are mandated.

\section{Statement of Ethics}

The study protocol was approved by the research institute's committee on human research.

\section{Disclosure Statement}

T.S. has received honorarium from Roche. G.C. has no conflicts of interest to declare.

\section{Funding Sources}

This work was supported by a research grant from the Israel Cancer Association.

\section{References}

1 Early Breast Cancer Trialists' Collaborative Group (EBCTCG). Effects of chemotherapy and hormonal therapy for early breast cancer on recurrence and 15-year survival: an overview of the randomised trials. Lancet. 2005 May;365(9472):1687-717.

2 Dowsett M, Cuzick J, Ingle J, Coates A, Forbes J, Bliss J, et al. Meta-analysis of breast cancer outcomes in adjuvant trials of aromatase inhibitors versus tamoxifen. J Clin Oncol. 2010 Jan;28(3):509-18.

3 Francis PA, Regan MM, Fleming GF, Láng I, Ciruelos E, Bellet M, et al. Adjuvant ovarian suppression in premenopausal breast cancer. N Engl J Med. 2015 Apr;372(17):1673.

4 Davies C, Pan H, Godwin J, Gray R, Arriagada R, Raina V, et al.; Adjuvant Tamoxifen: Longer Against Shorter (ATLAS) Collaborative Group. Long-term effects of continuing adjuvant tamoxifen to 10 years versus stopping at 5 years after diagnosis of oestrogen receptorpositive breast cancer: ATLAS, a randomised trial. Lancet. 2013 Mar;381(9869):805-16.

5 Cramer JA, Roy A, Burrell A, Fairchild CJ, Fuldeore MJ, Ollendorf DA, et al. Medication compliance and persistence: terminology and definitions. Value Health. 2008 Jan-Feb; 11(1):44-7.

6 Chlebowski RT, Kim J, Haque R. Adherence to endocrine therapy in breast cancer adjuvant and prevention settings. Cancer Prev Res (Phila). 2014 Apr;7(4):378-87.
7 Ayres LR, Baldoni AO, Borges AP, Pereira LR. Adherence and discontinuation of oral hormonal therapy in patients with hormone receptor positive breast cancer. Int J Clin Pharm. 2014 Feb;36(1):45-54.

8 Hershman DL, Shao T, Kushi LH, Buono D, Tsai WY, Fehrenbacher L, et al. Early discontinuation and non-adherence to adjuvant hormonal therapy are associated with increased mortality in women with breast cancer. Breast Cancer Res Treat. 2011 Apr; 126(2):529-37.

9 Makubate B, Donnan PT, Dewar JA, Thompson AM, McCowan C. Cohort study of adherence to adjuvant endocrine therapy, breast cancer recurrence and mortality. Br J Cancer. 2013 Apr;108(7):1515-24.

10 Chirgwin JH, Giobbie-Hurder A, Coates AS, Price KN, Ejlertsen B, Debled M, et al. Treatment Adherence and Its Impact on Disease-Free Survival in the Breast International Group 1-98 Trial of Tamoxifen and Letrozole, Alone and in Sequence. J Clin Oncol. 2016 Jul;34(21):2452-9.

11 Chodick G, Shalev V, Gerber Y, Heymann AD, Silber H, Simah V, et al. Long-term persistence with statin treatment in a not-for-profit health maintenance organization: a population-based retrospective cohort study in Israel. Clin Ther. 2008 Nov;30(11):2167-79.
12 Weingart SN, Brown E, Bach PB, Eng K, Johnson SA, Kuzel TM, et al. NCCN Task Force Report: oral chemotherapy. J Natl Compr Canc Netw. 2008 Mar;6 Suppl 3:S114.

13 Cohen R. Membership in sick funds. Jerusalem: National Insurance Institute; 2013.

14 Chodick G, Porath A, Alapi H, Sella T, Flash $\mathrm{S}$, Wood F, et al. The direct medical cost of cardiovascular diseases, hypertension, diabetes, cancer, pregnancy and female infertility in a large HMO in Israel. Health Policy. 2010 May;95(2-3):271-6.

15 Israel Center for Disease Control. Investigation into the completeness of the Israel Cancer Registry. Publication 230. Jerusalem: Israel Center for Disease Control; 2003. Hebrew.

16 Hershman DL, Kushi LH, Shao T, Buono D, Kershenbaum A, Tsai WY, et al. Early discontinuation and nonadherence to adjuvant hormonal therapy in a cohort of 8,769 early-stage breast cancer patients. J Clin Oncol. 2010 Sep; 28(27):4120-8.

17 He W, Fang F, Varnum C, Eriksson M, Hall P, Czene K. Predictors of Discontinuation of Adjuvant Hormone Therapy in Patients With Breast Cancer. J Clin Oncol. 2015 Jul;33(20): 2262-9. 
18 Smith SG, Sestak I, Howell A, Forbes J, Cuzick J. Participant-Reported Symptoms and Their Effect on Long-Term Adherence in the International Breast Cancer Intervention Study I (IBIS I). J Clin Oncol. 2017 Aug;35(23):266673.

19 Cluze C, Rey D, Huiart L, BenDiane MK, Bouhnik AD, Berenger $\mathrm{C}$, et al. Adjuvant endocrine therapy with tamoxifen in young women with breast cancer: determinants of interruptions vary over time. Ann Oncol. 2012 Apr;23(4):882-90.

20 Partridge AH, Wang PS, Winer EP, Avorn J. Nonadherence to adjuvant tamoxifen therapy in women with primary breast cancer. J Clin Oncol. 2003 Feb;21(4):602-6.

21 Anders CK, Hsu DS, Broadwater G, Acharya CR, Foekens JA, Zhang Y, et al. Young age at diagnosis correlates with worse prognosis and defines a subset of breast cancers with shared patterns of gene expression. J Clin Oncol. 2008 Jul;26(20):3324-30.

22 Gajdos C, Tartter PI, Bleiweiss IJ, Bodian C, Brower ST. Stage 0 to stage III breast cancer in young women. J Am Coll Surg. 2000 May; 190(5):523-9.

23 Hsieh KP, Chen LC, Cheung KL, Chang CS, Yang YH. Interruption and non-adherence to long-term adjuvant hormone therapy is associated with adverse survival outcome of breast cancer women-an Asian population-based study. PLoS One. 2014 Feb;9(2):e87027.
24 Paluch-Shimon S, Pagani O, Partridge AH, Abulkhair O, Cardoso MJ, Dent RA, et al. ESO-ESMO 3rd international consensus guidelines for breast cancer in young women (BCY3). Breast. 2017 Oct;35:203-17.

25 Llarena NC, Estevez SL, Tucker SL, Jeruss IS. Impact of Fertility Concerns on Tamoxifen Initiation and Persistence. J Natl Cancer Inst. 2015 Aug;107(10):107.

26 Briesacher BA, Andrade SE, Fouayzi H, Chan KA. Comparison of drug adherence rates among patients with seven different medical conditions. Pharmacotherapy. 2008 Apr; 28(4):437-43.

27 Murphy CC, Bartholomew LK, Carpentier MY, Bluethmann SM, Vernon SW. Adherence to adjuvant hormonal therapy among breast cancer survivors in clinical practice: a systematic review. Breast Cancer Res Treat. 2012 Jul;134(2):459-78.

28 Turner JP, Shakib S, Singhal N, Hogan-Doran J, Prowse R, Johns S, et al. Prevalence and factors associated with polypharmacy in older people with cancer. Support Care Cancer. 2014 Jul;22(7):1727-34.

29 Calip GS, Xing S, Jun DH, Lee WJ, Hoskins KF, Ko NY. Polypharmacy and Adherence to Adjuvant Endocrine Therapy for Breast Cancer. J Oncol Pract. 2017 May;13(5):e451-62.
30 Robinson B, Dijkstra B, Davey V, Tomlinson S, Frampton C. Adherence to Adjuvant Endocrine Therapy in Christchurch Women with Early Breast Cancer. Clin Oncol (R Coll Radiol). 2018 Jan;30(1):e9-15.

31 Kann S, Schmid SM, Eichholzer M, Huang DJ, Amann E, Güth U. The impact of overweight and obesity on breast cancer: data from Switzerland, so far a country little affected by the current global obesity epidemic. Gland Surg. 2014 Aug;3(3):181-97.

32 Nyrop KA, Williams GR, Muss HB, Shachar SS. Weight gain during adjuvant endocrine treatment for early-stage breast cancer: what is the evidence? Breast Cancer Res Treat. 2016 Jul;158(2):203-17.

33 Grymonpre R, Cheang M, Fraser M, Metge C, Sitar DS. Validity of a prescription claims database to estimate medication adherence in older persons. Med Care. 2006 May;44(5): 471-7.

34 Nattinger AB, Laud PW, Bajorunaite R, Sparapani RA, Freeman JL. An algorithm for the use of Medicare claims data to identify women with incident breast cancer. Health Serv Res. 2004 Dec;39(6 Pt 1):1733-49.

35 Chubak J, Yu O, Pocobelli G, Lamerato L, Webster J, Prout MN, et al. Administrative data algorithms to identify second breast cancer events following early-stage invasive breast cancer. J Natl Cancer Inst. 2012 Jun; 104(12):931-40. 